\title{
Analysis of Characteristics, Methods of Suicide, and Clinical Outcomes in Elderly Suicide Attempters in South Korea by Age Subgroup
}

Jae Hee Lee, ${ }^{1}$ Duk Hee Lee ${ }^{1, *}$

${ }^{1}$ Department of Emergency Medicine, College of medicine, Ewha Womans University, Seoul, South Korea

\section{*Correspondence}

ewhain78@gmail.com

(Duk Hee Lee)

\begin{abstract}
Introduction: As the elderly comprise $14.3 \%$ of the South Korean population, suicide among the elderly has become a significant public concern. Methods: This study retrospectively analyzed data from the Emergency Department-Based Injury In-depth Surveillance nationwide of South Korea. Patients aged $\geq 65$ years old who intentionally caused self-injury were included. These elderly patients were subdivided into age groups, and their associated characteristics and correlation between suicide attempt methods and the clinical outcomes were analyzed. Results: A total of 5,333 cases were analyzed. The mean age of the subjects was 75.1 years old, comprising 3,039 males $(57.0 \%)$ and 2,294 females (43.0\%). Substance exposure was the most frequent method across all age groups. In terms of risk factors of admission, drowning, hanging, and asphyxia showed the following results: OR 2.372 for the first group; OR 2.224 for the second group; and OR 5.606 for the third group. Fall/slip was identified as a risk factor of admission in the first and second groups (OR 5.016 for the first group; OR 5.101 for the second group). In terms of risk factors of mortality, drowning, hanging, and asphyxia showed the following results: OR 9.066 for the first group; OR 7.320 for the second group; and OR 7.135 for the third group. With regard to fall/slip, the results were OR 14.596 for the first group; OR 10.096 for the second group; and OR 24.167 for the third group. Conclusions: This study showed that clinical outcomes were different according to the suicide-related characteristics and chosen suicide method. Based on these results, it is necessary to prepare measures to prevent suicide of the elderly in the future.
\end{abstract}

\section{Keywords}

Elderly, Emergency department, Suicide attempter, Suicide methods

\section{Introduction}

Suicide is a major public health concern in many countries. Around 800,000 people die by suicide annually; in other words, one person commits suicide around the world every 40 seconds (World Health Organization). With the growth of the elderly population, suicide among the elderly has emerged as a serious public health issue. Research has shown that suicide rates generally increase with age $[1,2]$. Upon analyzing a population aged 60 years or older in units of 5 years, a study by Shah et al. (2016) showed a tendency of the elderly suicide rate to increase during the following ages: from $60-64$ to 90-94 years old in men, and from 60-64 to 85-89 years old in women [3]. Among age groups, suicide was especially prevalent in those aged over 70 of both sexes. [4]

Suicide in the elderly population is also an important public health concern in South Korea as the country has a rapidly aging population. In $2018,14.4 \%$ of South Korea's population was determined to be $\geq 65$ years old. Due to the rapidly aging population in Korea, seniors aged 65 or older in 2019 as it is expected to be $14.9 \%, 20.3 \%$ in 2025 , and $46.5 \%$ in 2067 [5]. Furthermore, elderly age groups are more likely to attempt suicide than other age groups because of reasons such as bereavement after death of spouse or relatives, suffering from a chronic physical illness, and economic difficulties due to retirement and reduced income sources. It was found that about $30 \%$ of Koreans aged 65 or older have thought of wanting to die in the last year. [6] South Korea had the highest suicide rate among all Organization for Economic Co-operation and Development (OECD) countries in 2017, with 24.6 suicides for every 100,000 people [7]. Based on age group, the suicide rates in 2017 were 36.9 for every 100,000 people in their 60 s, 62.5 for every 100,000 people in their 70 s, and 83.7 for every 100,000 people in their 80 s or older [8]. Compared to other OECD countries, the suicide rate in South Korea is two times higher in the age groups between 20 and 60 , and three times higher among those in their 70s and 80s [9]. The suicide rate among the elderly is so high that it cannot be compared with other age groups. In Japan, which is known to have a relatively 
TA B L E 1. General characteristics of age groups of elderly suicide attempters at the ED during 2011-2016.

\begin{tabular}{|c|c|c|c|c|c|c|c|c|c|}
\hline \multirow[b]{3}{*}{ Age (years, mean \pm SD) } & \multicolumn{2}{|c|}{ Total } & \multicolumn{2}{|c|}{$65-74$ yrs } & \multicolumn{2}{|c|}{$75-84$ yrs } & \multicolumn{2}{|c|}{$\geq 85 \mathrm{yrs}$} & \multirow{3}{*}{$\begin{array}{l}\text { p-value } \\
<\mathbf{0 . 0 0 1}\end{array}$} \\
\hline & \multicolumn{2}{|c|}{$(\mathrm{n}=5,333)$} & \multicolumn{2}{|c|}{$(\mathrm{n}=2,720)$} & \multicolumn{2}{|c|}{$(\mathrm{n}=2,078)$} & \multicolumn{2}{|c|}{$(\mathrm{n}=535)$} & \\
\hline & 75.1 & \pm 6.7 & 69.7 & \pm 2.9 & 78.6 & \pm 2.3 & 88.3 & \pm 3.5 & \\
\hline Sex & & & & & & & & & $<\mathbf{0 . 0 0 1}$ \\
\hline Male & 3,039 & -57 & 1,623 & -59.7 & 1,183 & -56.9 & 233 & -43.6 & \\
\hline Female & 2,294 & -43 & 1,097 & -40.3 & 895 & -43.1 & 302 & -56.4 & \\
\hline \multicolumn{10}{|l|}{ Mode of arrival } \\
\hline 119 & 2,956 & -55.4 & 1,527 & -56.1 & 1,128 & -54.3 & 301 & -56.3 & 0.404 \\
\hline Walk-in (include car, foot, etc.) & 657 & -12.3 & 365 & -13.4 & 230 & -11.1 & 62 & -11.6 & 0.042 \\
\hline Private ambulance & 1,683 & -31.6 & 808 & -29.7 & 708 & -34.1 & 167 & -31.2 & 0.005 \\
\hline Police & 8 & -0.2 & 6 & -0.2 & 1 & 0 & 1 & -0.2 & 0.221 \\
\hline Air & 23 & -0.4 & 10 & -0.4 & 10 & -0.5 & 3 & -0.6 & 0.789 \\
\hline Others & 5 & -0.1 & 4 & -0.1 & 0 & 0 & 1 & -0.2 & 0.136 \\
\hline Unknown & 1 & 0 & 0 & 0 & 1 & 0 & 0 & 0 & 0.49 \\
\hline Time interval from injury to ED visit (hrs) & 2 & $(0.00-4.00)$ & 2 & $(0.0-5.0)$ & 2 & $(0.0-4.0)$ & 1 & $(0.0-4.0)$ & 0.043 \\
\hline Day of presentation & & & & & & & & & 0.437 \\
\hline Weekday (Mon-Thu) & 3,035 & -56.9 & 1,525 & -56.1 & 1,203 & -57.9 & 307 & -57.4 & \\
\hline Weekend (Fri-Sun) & 2,298 & -43.1 & 1,195 & -43.9 & 875 & -42.1 & 228 & -42.6 & \\
\hline \multicolumn{10}{|l|}{ Time of presentation } \\
\hline Day (7-14h) & 2,066 & -38.7 & 996 & -36.6 & 839 & -40.4 & 231 & -43.2 & 0.003 \\
\hline Evening (15-22h) & 2,323 & -43.6 & 1,208 & -44.4 & 901 & -43.4 & 214 & -40 & 0.166 \\
\hline Night (23-6h) & 944 & -17.7 & 516 & -19 & 338 & -16.3 & 90 & -16.8 & 0.044 \\
\hline \multicolumn{10}{|l|}{ Insurance } \\
\hline National health insurance & 4,147 & -77.8 & 2,084 & -76.6 & 1,643 & -79.1 & 420 & -78.5 & 0.119 \\
\hline Self-pay (uninsured) & 841 & -15.8 & 447 & -16.4 & 316 & -15.2 & 78 & -14.6 & 0.375 \\
\hline Medicaid beneficiary & 328 & -6.2 & 177 & -6.5 & 116 & -5.6 & 35 & -6.5 & 0.382 \\
\hline Vehicle & 2 & 0 & 1 & 0 & 1 & 0 & 0 & 0 & 1 \\
\hline Private insurance & 3 & -0.1 & 1 & 0 & 1 & 0 & 1 & -0.2 & 0.331 \\
\hline Others & 12 & -0.2 & 10 & -0.4 & 1 & 0 & 1 & -0.2 & 0.067 \\
\hline \multicolumn{10}{|l|}{ Alcohol ingestion } \\
\hline No evidence of drinking & 3,392 & -63.6 & 1,572 & -57.8 & 1,413 & -68 & 407 & -76.1 & $<\mathbf{0 . 0 0 1}$ \\
\hline Patient drinking & 1,215 & -22.8 & 786 & -28.9 & 380 & -18.3 & 49 & -9.2 & $<\mathbf{0 . 0 0 1}$ \\
\hline Drinking all & 2 & 0 & 1 & 0 & 1 & 0 & 0 & 0 & 1 \\
\hline Unknown & 724 & -13.6 & 361 & -13.3 & 284 & -13.7 & 79 & -14.8 & 0.643 \\
\hline
\end{tabular}

high suicide rate, the suicide rate per 100,000 people of those aged $65-74$ and above 75 was 17.9 . The suicide rate among the elderly was 14.6 , which is much lower than that of 61.8 (65-74 years old) and 80.4 (75 years or older) in Korea [6].

With a view to prevent suicide in the elderly, several studies have been conducted to investigate epidemiological data or examine risk factors of suicide in said age group [10-16]. According to a study by Vadysinghe et al., $32.1 \%$ of the unnatural deaths of the elderly were because of suicide, and poisoning $(59.6 \%)$ was the most common method of suicide. [17] However, with the increase in the average life expectancy and improvement of the health status of the elderly population, the elderly population may have to be subdivided into age groups for analysis. While there has been research on suicide in the elderly via age group subdivision, this research focused on identifying the risk factors of suicide attempts. Studies have shown that identification of the availability of lethal means of suicide and the management of such means is as effective in the prevention of suicide as the prevention of the suicide attempt itself $[18,19]$. This study sought to further explore the suicide-related characteristics and clinical outcomes according to the methods of suicide attempt among elderly individuals who were admitted to the emergency department (ED) due to injuries from a suicide attempt. Furthermore, we analyze the 
T A B L E 2. Injury characteristics and clinical outcomes of age groups of elderly suicidal attempters at the ED.

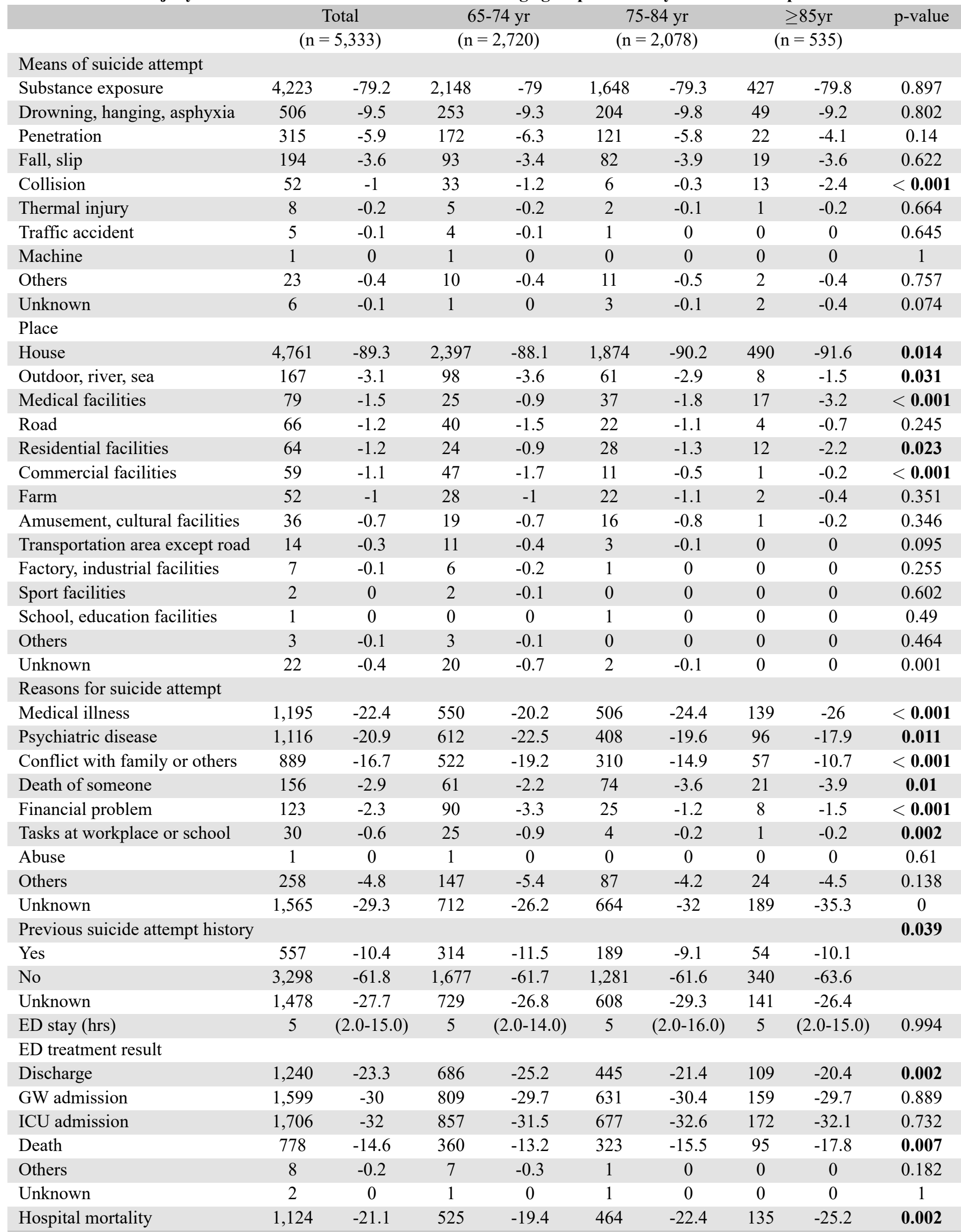

"ED death" includes deaths at the ED and deaths after admission within 24 hours.

"Hospital mortality" includes ED death and death after admission. 
results by subdividing the elderly into age-specific subgroups.

\section{Methods}

\subsection{Setting and Data Collection}

This study was a retrospective analysis of data from the Emergency Department-Based Injury In-depth Surveillance of the Korea Centers for Disease Control and Prevention (KCDC) from 2011 to 2016. The Emergency Department-Based Injury In-depth Surveillance is a data collection system that collects data on basic epidemiology, treatment, and outcomes of injured patients admitted to the ED. Implemented in 2006, the collection system involved 20 agencies from 2011 to 2014, and 23 agencies since 2015. Each hospital employs personnel that are responsible for data entry and quality control, and are regularly trained and supervised by the Korea Centers for Disease Control and Prevention.

In this study, a "suicide attempter" is defined as a patient who falls within the scope of the "suicide, self-harm" item in the "intentionality of injury" items of the Emergency Department-Based Injury In-depth Surveillance. The exclusion criteria were those under 65 years of age, and those who fell under the "unintentional/assault/others/unknown" item in the "intentionality of injury" items.

\subsection{Outcome Measure}

The study population was divided into three groups according to age distribution: $65-74$ years, $75-84$ years, and 85 years-

The general characteristics used in the analysis were sex, age, mode of ED arrival, date/time of ED visit, date/time of injury occurrence, insurance types, and alcohol ingestion. The following were the injury characteristics: mechanism of injury, place where the injury occurred, reason for suicide attempt, previous suicide attempt history, date/time of ED departure, ED treatment results, and date of death. Based on these variables, the time interval from the injury to the ED visit and the duration of the ED stay were calculated. The primary outcome of the study was admission to the hospital. Patients with the admission status "admission" or "inter-hospital transfer" under the "ED treatment results" item were classified as admitted. Meanwhile, the secondary outcome was hospital mortality. Hospital mortality included cases of death in the ED, and dates of death recorded for admitted patients in the "emergency treatment results" item.

\subsection{Statistical Analysis}

The data are expressed as mean with standard deviation of median, with interquartile ranges for continuous variables and numbers with percentages for categorical variables. General characteristics, injury characteristics, and clinical outcomes were analyzed according to age groups. For items requiring statistical verification, the one-way analysis of variance (ANOVA) test or Kruskal-Wallis test was used for continuous variables, and a chi-square test was used for categorical variables. To examine the risk of admission and mortality for each suicide attempt method under each age group, the data were reclassified into admission/discharge and survival/mortality groups, and their respective rates were compared. Once the suicide attempt methods that showed significant differences between the admission/discharge and the survival/mortality groups were identified, a multivariate regression analysis was performed for each attempt method based on sex, mode of arrival, time interval from injury to ED visit, day and time of presentation, alcohol ingestion, place of sustaining injury, reasons for suicide attempt, and previous suicide attempt history. Multiple logistic regression using backward stepwise selection (likelihood ratio) was performed, and the remaining variables with $\mathrm{p}$-values less than 0.05 were listed in the tables. A two-tailed p-value of $<0.05$ was considered statistically significant. The statistical analyses were carried out using SPSS version 21.0 for Windows software (SPSS Inc., Chicago, IL, USA).

\subsection{Ethical Considerations}

This study was conducted with approval from the Institutional Review Board (IRB) of Ewha Woman's University Mokdong Hospital (No. 2020-06-018). The KCDC is the authority for accessing the data. Informed consent was waived by the IRB because patient information was anonymized before the analysis.

\section{Results}

1,537,617 cases were collected through the Emergency Department-Based Injury In-depth Surveillance, from which a total of 5,333 cases were enrolled in this research (Fig. ??). The subjects had a mean age of 75.1 years old, and consisted of 3,039 males (57.0\%) and 2,294 females (43.0\%). Among the subjects, $2,720(51.0 \%)$ were in the age band of $65-74$; $2,078(39.0 \%)$ were in the age band of $75-84$; and $535(10.0 \%)$ were aged 85 and older.

\subsection{General characteristics of elderly suicide attempters at the ED (Table 1)}

The general characteristics of the subjects, which are contained in Table 1, were compared among the three study groups (6574 years as the 1 st group, 75-84 years as the 2 nd group, and $\geq 85$ years as the 3 rd group). The group with the highest ratio of male patients was the 1 st group ( $59.7 \%$ vs $56.9 \%$ vs $43.6 \%)$. On the other hand, the group with the highest female ratio was the 3 rd group ( $40.3 \%$ vs $43.1 \%$ vs $56.4 \%$ ). With regard to the mode of arrival, the ratio of walk-in and private ambulance cases showed significant differences among the three groups. The group with the highest walk-in ratio was the 1st group (13.4\% vs $11.1 \%$ vs $11.6 \%$ ), and private ambulance cases had the highest ratio in the 3 rd group $(29.7 \%$ vs $34.1 \%$ vs $31.2 \%)$. The time interval from injury to ED visit was found to be significantly shorter in the 3 rd group ( 2 vs 2 vs 1 ). In terms of the time of presentation, the ratio of day time was the highest in the 3 rd group ( $36.6 \%$ vs $40.4 \%$ vs $43.2 \%$ ), and the ratio of night time was the highest in the 1 st group $(19.0 \%$ vs $16.3 \%$ vs $16.8 \%)$. The ratio of "no evidence of drinking" was highest in the 3rd group ( $57.8 \%$ vs $68.0 \%$ vs $76.1 \%$ ), and that of patient drinking was highest in the 1 st group $(28.9 \%$ vs $18.3 \%$ vs $9.2 \%)$. 
of elderly suicidal attempters at the ED.

Total $(\mathrm{n}=5,323) \quad$ p-value $\quad 65-74 \mathrm{yr},(\mathrm{n}=2,712) \quad$ p-value $\quad 75-84 \mathrm{yr},(\mathrm{n}=2,076) \quad$ p-value $\geq 85 \mathrm{yr},(\mathrm{n}=535) \quad \mathrm{p}$-value

$(+)$

$(-)$

(+)

$(-)$

(+)

(-)

(+)

Admission

Sex $<0.001$

$<0.001$

0.081

0.013

Male

$\begin{array}{lllll}619 & -49.9 & 2,411 & -59\end{array}$

$\begin{array}{lllll}346 & -50.4 & 1,270 & -62.7\end{array}$

$\begin{array}{llll}237 & -53.3 & 944 & -57.9\end{array}$

$\begin{array}{lllll}36 & -33 & 197 & -46.2\end{array}$

Female

$\begin{array}{llll}621 & -50.1 & 1,672 & -41\end{array}$

$\begin{array}{llll}340 & -49.6 & 756 & -37.3\end{array}$

$\begin{array}{llll}208 & -46.7 & 687 & -9.8\end{array}$

$\begin{array}{llll}73 & -67 & 229 & -53.8\end{array}$

Means of suicide attempt

$\begin{array}{llllllllllllllllllllllll}\text { Substance exposure } & 1,032 & -83.2 & 3,185 & -78 & <\mathbf{0 . 0 0 1} & 567 & -82.7 & 1,576 & -77.8 & \mathbf{0 . 0 0 7} & 379 & -85.2 & 1,268 & -77.7 & \mathbf{0 . 0 0 1} & 86 & -78.9 & 341 & -80\end{array}$

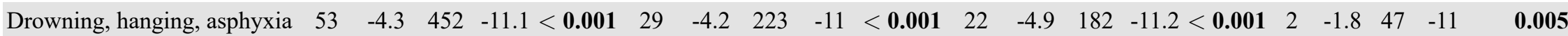

Penetration

$\begin{array}{llllllllllllllllllllll}100 & -8.1 & 214 & -5.2 & <\mathbf{0 . 0 0 1} & 58 & -8.5 & 113 & -5.6 & \mathbf{0 . 0 0 7} & 33 & -7.4 & 88 & -5.4 & 0.107 & 9 & -8.3 & 13 & -3.1\end{array}$

$\mathbf{0 . 0 2}$

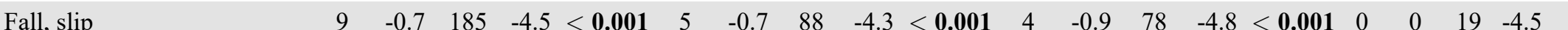

$\begin{array}{llllllllllllllllllllll}\text { Collision } & 33 & -2.7 & 18 & -0.4 & <\mathbf{0 . 0 0 1} & 19 & -2.8 & 13 & -0.6 & <\mathbf{0 . 0 0 1} & 4 & -0.9 & 2 & -0.1 & \mathbf{0 . 0 2 2} & 10 & -9.2 & 3 & -0.7 & <\mathbf{0 . 0 0 1}\end{array}$

Thermal injury

Traffic accident

$\begin{array}{llllllllll}2 & -0.2 & 6 & -0.1 & 1 & 2 & -0.3 & 3 & -0.1 & 0.606\end{array}$

$\begin{array}{lll}0 & 2 & -0\end{array}$

1

$\begin{array}{lllr}0 & 0 & 0 & 0\end{array}$

Machine

$\begin{array}{lllllllllllllllllll}1 & -0.1 & 0 & 0 & 0.233 & 1 & -0.1 & 0 & 0 & 0.253 & 0 & 0 & 0 & 0 & - & 0 & 0 & 0 & 0\end{array}$

Others

$\begin{array}{lllll}7 & -0.6 & 15 & -0.4 & 0.447\end{array}$

Unknown

$\begin{array}{llllll}2 & -0.2 & 4 & -0.1 & 0.629\end{array}$

$\begin{array}{lr}4 & -0.6 \\ 0 & 0\end{array}$

Mortality

\begin{tabular}{|c|c|c|c|c|c|c|c|c|c|c|c|c|c|c|c|c|c|c|c|}
\hline Sex & & & & & $<\mathbf{0 . 0 0 1}$ & & & & & $<\mathbf{0 . 0 0 1}$ & & & & & $<\mathbf{0 . 0 0 1}$ & & & & 0.001 \\
\hline Male & 2,275 & $5-54.2$ & 755 & -67.2 & & 1,244 & -56.9 & 372 & -70.9 & & 873 & -54.2 & 308 & -66.4 & & 158 & $8-39.5$ & $75-55.6$ & \\
\hline Female & 1,924 & $7-45.8$ & 369 & -32.8 & & 943 & -43.1 & 153 & -29.1 & & 739 & -45.8 & 156 & -33.6 & & 242 & -60.5 & $60-44.4$ & \\
\hline Means of suicide attempt & & & & & & & & & & & & & & & & & & & \\
\hline Substance exposure & 3,605 & $5-85.9$ & 612 & -54.4 & $t<\mathbf{0 . 0 0 1}$ & 1,868 & -85.4 & 275 & -52.4 & $t<\mathbf{0 . 0 0 1}$ & 1,386 & -86 & 261 & -56.3 & $<0.001$ & 351 & $1-87.8$ & $76-56.3$ & $<0.001$ \\
\hline Drowning, hanging, asphyxia & 165 & -3.9 & 340 & -30.2 & $<\mathbf{0 . 0 0 1}$ & 86 & -3.9 & 166 & -31.6 & $5<\mathbf{0 . 0 0 1}$ & 66 & -4.1 & 138 & -29.7 & $<\mathbf{0 . 0 0 1}$ & 13 & -3.3 & $36-26.7$ & $<\mathbf{0 . 0 0 1}$ \\
\hline Penetration & 299 & -7.1 & 15 & -1.3 & $<0.001$ & 163 & -7.5 & 8 & -1.5 & $<\mathbf{0 . 0 0 1}$ & 118 & -7.3 & 3 & -0.6 & $<0.001$ & 18 & -4.5 & $\begin{array}{ll}4 & -3\end{array}$ & 0.473 \\
\hline Collision & 50 & -1.2 & 1 & -0.1 & 0.001 & 32 & -1.5 & 0 & 0 & 0.005 & 6 & -0.4 & 0 & 0 & 0.348 & 12 & -3 & $1 \quad-0.7$ & 0.201 \\
\hline Thermal injury & 6 & -0.1 & 2 & -0.2 & 1 & 5 & -0.2 & 0 & 0 & 0.59 & 1 & -0.1 & 1 & -0.2 & 0.397 & 0 & 0 & -0.7 & 0.252 \\
\hline Traffic accident & 4 & -0.1 & 1 & -0.1 & 1 & 3 & -0.1 & 1 & -0.2 & 0.577 & 1 & -0.1 & 0 & 0 & 1 & 0 & 0 & 0 & - \\
\hline Machine & 1 & 0 & 0 & 0 & 1 & 1 & 0 & 0 & 0 & 1 & 0 & 0 & 0 & 0 & - & 0 & 0 & 0 & - \\
\hline Others & 20 & -0.5 & 2 & -0.2 & 0.2 & 9 & -0.4 & 1 & -0.2 & 0.698 & 9 & -0.6 & 1 & -0.2 & 0.702 & 2 & -0.5 & 0 & 1 \\
\hline Unknown & 6 & -0.1 & 0 & 0 & 0.354 & 1 & 0 & 0 & 0 & 1 & 3 & -0.2 & 0 & 0 & 1 & 2 & -0.5 & 0 & 1 \\
\hline
\end{tabular}




\subsection{Injury characteristics and clinical outcomes of elderly suicide attempters at the ED (Table 2)}

The injury characteristics and clinical outcomes, which are displayed in Table 2, were analyzed among the three study groups. Except for "collision," there was no significant difference in the proportion of means of suicide attempt. The proportion of collision was highest in the 3 rd group $(1.2 \%$ vs $0.3 \%$ vs $2.4 \%$ ). With regard to the reasons for suicide attempts, the ratio of medical illness and the death of someone were highest in the 3rd group, while the ratios of psychiatric disease, conflict with family or others, financial problems, and tasks at the workplace or school were the highest in the 1st group. The ratio of previous suicide history was highest in the 1st group $(11.5 \%)$. In relation to clinical outcome, the ratio of discharge was highest in the 1 st group ( $25.2 \%$ vs $21.4 \%$ vs $20.4 \%$ ), while that of death in the ED was highest in the 3 rd group (13.2\% vs $15.5 \%$ vs $17.8 \%)$. Hospital mortality was also highest in the 3rd group ( $19.4 \%$ vs $22.4 \%$ vs $25.2 \%$ ).

\subsection{Comparison of suicide attempt methods that affect admission and mortality among age groups in elderly suicidal attempters at the ED (Table 3)}

A subgroup analysis was performed to analyze differences in suicide attempt methods according to admission and mortality status (Table 3). As a result of the analysis based on admission status, substance exposure was the most frequent attempt method, and was found to affect admission. In all three groups, drowning/hanging/asphyxia and fall/slip had a significant impact on admission.

After dividing the subjects into two groups based on mortality status and performing a subgroup analysis, the attempt methods of drowning/hanging/asphyxia and fall/slip were found to have a significant effect on mortality in all age groups. In the case of substance exposure, the ratio was significantly higher in the survival group across all three age groups. The ratio of penetration was higher in the survival group for the 1st and 2nd age groups.

\subsection{Multivariable logistic regression analysis for admission and mortality}

Multivariate logistic regression analysis was performed on the five suicide attempt methods, with significant differences between admission/discharge and survival/mortality groups, in order to assess the risk of admission and mortality based on suicide attempt methods among elderly suicide attempters (Table 4). In terms of risk factors of admission, drowning, hanging, and asphyxia showed the following results: OR 2.372 [CI] 1.563-3.599 for the first group; OR 2.224 [CI] 1.388-3.564 for the second group; and OR 5.606 [CI] 1.390-24.010 for the third group. Fall/slip was identified to be a risk factor in the first and second groups (OR 5.016 [CI] 2.013-12.500 for the first group; OR 5.101 [CI] 1.846-14.098 for the second group).

In terms of risk factors of mortality, drowning/hanging/asphyxia showed the following results: OR $9.066[\mathrm{CI}]$ 6.691-12.284 for the first group; OR $7.320[\mathrm{CI}]$
5.181-10.342 for the second group; and OR 7.135 [CI] 3.499-14.550 for the third group. In the case of fall/slip, the results were: OR 14.596 [CI] 8.520-25.005 for the first group; OR 10.096 [CI] 5.831-17.480 for the second group; and OR 24.167 [CI] 5.214-112.025 for the third group.

\section{Discussion}

Through analyzing the general characteristics of elderly patients who were admitted to the ED due to suicide attempts, we have confirmed the general demographic characteristics of each age subgroup. The results showed that the proportion of women increased, and that of men decreased, from the 1st age group to the 3rd age group. Among the elderly patients who attempted suicide aged 85 or older, the proportion of women was $56.4 \%$, while that of men was $43.6 \%$ (Table 1). However, the proportion of elderly men and women who died did not reverse as age increased, with $55.6 \%$ of men and $44.4 \%$ of women comprising those aged 85 or older who died (Table 3). This indicates that the incidence of suicide attemptersincluding cases of mortality and survival — was high in women, but more men died from their suicide attempts. According to the National Emergency Department Information System (NEDIS), 14,803 male (44.3\%) and 18,648 female (55.7\%) suicide attempters visited the ED of an emergency medical service institution in South Korea in 2018, indicating a higher number of female suicide attempters [20]. On the other hand, according to Statistics Korea, the number of deaths by suicide was 2,591 for men and 1,002 for women among those aged 65 or older; and 730 for men and 417 for women among those aged 80 or older. Considering that the ratio of men in the Korean population - among those aged 80 or older-is $30.6 \%$, this indicates that both the ratio of suicide attempts and that of suicide attempt successes are higher in men [5]. In 2018, the incidence of suicide for every 100,000 people in South Korea was: 82.2 for men and 23.7 for women at age 65; and 138.5 for men and 37.3 for women aged 80 or older [21]. This indicates a difference of more than three times between men and women. Such a difference in the suicide and attempt rates of men and women are similar worldwide. According to a systemic review of 53 studies published in Europe and America between 2005 and 2015, men (36\% of the studies) and the elderly ( $28 \%$ of the studies) commit suicide more frequently, while women (30\% of the studies) and young people (17\% of the studies) demonstrate a higher number of attempts and suicidal behavior. [22]. According to the analysis results of data from the WHO Mortality Database between 2004 and 2009 , the suicide mortality rate of men aged 65-74 was 28.6 , and that of women was 7.5 ; the suicide mortality rate for men aged 75 or older was 40.2, and that of women was 10.4 [1]. In a study of the general population of Andalusia, Spain, the prevalence of attempted suicide did not vary between the sexes, whereas the prevalence of deaths by suicide was three-fold higher among males than among females, and increased with higher age. [4]

As shown by the results of this study, for those aged between 65 and 74, the rate of injury was higher when the elderly visited the ED at evening time; when there was alcohol ingestion; and in outdoor places or commercial facilities. For those aged 85 
TA B L E 4. Adjusted odds ratio and $95 \%$ confidence interval of methods of suicide for admission and mortality.

\begin{tabular}{|c|c|c|c|c|c|c|c|c|c|}
\hline \multirow{2}{*}{ Variables } & \multicolumn{3}{|c|}{$65-74$ yrs } & \multicolumn{3}{|c|}{$75-84$ yrs } & \multicolumn{3}{|c|}{$\geq 85 \mathrm{yrs}$} \\
\hline & OR & $(95 \% \mathrm{CI})$ & $\mathrm{p}$-Value & OR & $(95 \% \mathrm{CI})$ & p-Value & OR & $(95 \% \mathrm{CI})$ & p-Value \\
\hline \multicolumn{10}{|l|}{ Admission } \\
\hline Substance exposure & - & - & - & 0.617 & $(0.459-0.829)$ & 0.001 & - & - & - \\
\hline Drowning, hanging, asphyxia & 2.372 & $(1.563-3.599)$ & 0 & 2.224 & $(1.388-3.564)$ & 0.001 & 5.606 & $(1.309-24.010)$ & 0.02 \\
\hline Penetration & 0.535 & $(0.381-0.750)$ & 0 & - & - & - & 0.317 & $(0.122-0.825)$ & 0.019 \\
\hline Fall, slip & 5.016 & $(2.013-12.500)$ & 0.001 & 5.101 & $(1.846-14.098)$ & 0.002 & - & - & - \\
\hline Collision & 0.187 & (0.091-0.385) & 0 & 0.157 & $(0.028-0.876)$ & 0.035 & 0.058 & $(0.014-0.239)$ & 0 \\
\hline \multicolumn{10}{|l|}{ Mortality } \\
\hline Substance exposure & 0.253 & $(0.020-0.316)$ & 0 & 0.271 & $(0.210-0.349)$ & 0 & 0.22 & $(0.135-0.360)$ & 0 \\
\hline Drowning, hanging, asphyxia & 9.066 & $(6.691-12.284)$ & 0 & 7.32 & $(5.181-10.342)$ & 0 & 7.135 & $(3.499-14.550)$ & 0 \\
\hline Penetration & 0.145 & $(0.067-0.315)$ & 0 & 0.072 & $(0.022-0.229)$ & 0 & - & - & - \\
\hline Fall, slip & 14.596 & $(8.520-25.005)$ & 0 & 10.096 & $(5.831-17.480)$ & 0 & 24.167 & $(5.214-112.025)$ & 0 \\
\hline Collision & - & - & - & - & - & - & - & - & - \\
\hline
\end{tabular}

or older, the rate of injury was higher when they visited ED during daytime; and in medical facilities, residential facilities, and houses. For those aged between 65 and 74 , the following reasons for suicide attempt accounted for a high proportion of cases: psychiatric disease, conflict with family or others, and reasons related to tasks at the workplace. For those aged 85 or older, the following reasons for their attempt accounted for a high proportion of cases: the death of someone, and medical illness. The most common reason for suicide attempt by age group was psychiatric disease in individuals aged 6574 years old, and medical illness in those aged $75-85$. This may be because among those aged 65 or older, the 1 st group is younger in comparison; thus, they are more physically active, have better health conditions, and more external and social activities. These are reflected in the findings of this study. For suicide attempts due to psychiatric disease, positive mental health was shown to moderate the impact of depression on suicidal ideation. Future studies on the suicide risk of elderly patients should consider the impact of positive mental health as well as psychiatric disorders [23]. An important characteristic of suicide among the elderly is that suicide attempts because of medical illness account for the largest proportion as the age increases. Even in the absence of psychiatric problems or terminal illnesses, most elderly individuals experience irreversible decline in physical function due to aging. For this reason, there is a high tendency of attempting suicide among the elderly. All humans undergo irreversible aging, which raises numerous ethical concerns regarding the acceptance of choosing to commit suicide. Whether to admit the rationale of suicide of the elderly should be further investigated in future studies, and clinicians should take the findings into consideration when dealing with elderly patients [24, 25].

In order to prevent suicide, a multifaceted approach is needed at the individual, relationship, community, and societal levels. Among these approaches, the societal level includes the identification of lethal methods of suicide and reducing access to such methods for persons at risk of suicide
[19]. The effect of controlling the availability of suicide methods has been introduced in many previous studiesone of which reported that suicide via pesticide was reduced with the regulation of paraquat, a lethal poisoning agent [18]. On the other hand, it has been reported that pharmaceutical drug poisoning increased upon the approval of over-thecounter drug sales [26]. As can be seen from these examples, understanding the characteristics of the methods of suicide provides important basic data for establishing preventive measures. In this study, an analysis of the methods used by suicide attempters who visited the ED showed that there was no significant difference among the age groups aside from the method of collision. The suicide attempt method with the highest incidence in the entire patient group was substance exposure, which accounted for $79.2 \%$ of cases. In both the admitted group and the mortality group, substance exposure also accounted for the highest proportion $(78.0 \%$ and $54.4 \%$, respectively). In a number of studies, intentional poisoning has been reported to account for the majority of suicide attempts, and various analyses on this method have been conducted [27-35]. To prevent suicide in the elderly, efforts should be made to reduce the availability of substances that are fatal when ingested. To this end, the existing research should be referenced, and research on the patterns of substance exposure in each elderly age group should be conducted, based on which measures to reduce access to poisonous substances can be suggested.

Although substance exposure was identified to be the suicide attempt method with the highest incidence, it is also important to consider its association with poor clinical outcomes. A subgroup analysis based on admission status and mortality showed that in the case of substance exposure, the ratio was higher in the discharge group than the admission group, and in the survival group than the mortality group. The adjusted OR for admission with regard to substance exposure was 0.617 (95\% CI $0.459-0.829)$ for the age group of $75-84$; and the adjusted OR for mortality was $0.253(95 \%$ 
CI $0.459-0.829)$ for the age group of $65-74 ; 0.271$ (95\% CI $0.210-0.349)$ for the age group of $75-84$, and $0.220(95 \%$ CI $0.135-0.360$ ) for the age group of 85 or older. On the other hand, in the case of drowning/hanging/asphyxia and fall/slip, their proportion in the admission group and the mortality group was high. Through multivariate analysis, drowning/hanging/asphyxia was identified as a significant risk factor of admission in all groups, while slip/fall was identified as a significant risk factor in the 65-74 and 75-84 age groups. The risk factors of mortality also showed similar results. In all groups, drowning/hanging/asphyxia and slip/fall were analyzed as risk factors. Among all suicide attempt methods, these two are deemed to be the most fatal methods which tend to cause admission and mortality. This is confirmed by suicide status data. In 2018 , the means of suicide with the highest resulting suicide rate was hanging - with a rate of 13.9 for every 100,000 persons - while the means with the second highest rate was falling, with a rate of 4.4 for every 100,000 persons [36]. Caregivers of elderly individuals who are at risk of attempting suicide should be educated about fatal suicide methods, such as drowning, hanging, asphyxia, and fall/slip. Preventing suicide among the elderly also requires social awareness of installing physical devices or controlling the surrounding environment.

According to reports, firearms are widely used as a means for suicide among the elderly [37, 38]. In particular, the use of firearms is the most lethal suicide method among American males [39]. Since private gun possession is not allowed in South Korea, however, the penetration rate of firearms is low in the country. Thus, the use of firearms or a gunshot was not included as a means of suicide in this study. Such differences can be attributed to characteristics unique to each country.

Furthermore, the psychosocial stressors for each age group in this study were different. This shows that stressors are different depending on the age band, although all subjects were aged 65 or older. It has been reported that stressors have a risky effect on fatal suicidal behaviors [40]. Ultimately, the elderly should not simply be regarded as a single group, but approached differently for each age band.

There are several limitations in this study. First, as the data was collected from all EDs nationwide, it is highly probable that self-injury or suicide patients were classified as "others or unknown" in the "intentional injury" category despite the review of data upon being sent. In particular, there are cases where the patient is unable to respond, such as in cases of death, or where he or she may have become incapable of expressing his or her intentions. In such cases, it is possible that mortality due to suicide was classified as "intentionality unknown." Second, a single case of injury was collected per patient. In cases where the patient has attempted suicide multiple times and through multiple methods, data were collected only for the method which was judged to have had the most significant impact on the prognosis of the patient — which may lead to biases in the data. It was not possible to analyze the risks that could appear when multiple attempt methods were used. In addition, since the data consists of injury data from the $\mathrm{ED}$, the sociological factors relating to suicide have not been investigated in the study, which may be another limitation.

\section{Conclusions}

Through the analysis of the general characteristics of elderly patients who were admitted to the ED due to suicide attempts, we confirmed the general demographic characteristics of each age subgroup. With regard to suicide attempt methods, substance exposure was the most frequent method across all age groups. However, it was not a significant factor of admission and mortality. Drowning, hanging, and asphyxia were identified to be significant factors of admission and mortality in all groups aged 65 or older. Further, the fall/slip method was identified as a high risk factor of admission for patients under 85 , and is a significant mortality factor for all subgroups. In particular, the fall/slip method showed significantly high lethality in patients aged 85 or older. Therefore, to prevent suicide among the elderly, it is necessary to reduce their access to drugs and to monitor and physical obstruction devices for fatal methods.

\section{ACKNOWLEDGMENTS}

We would like to thank Hye Ah Lee for advice on statistical analysis.

\section{CONFLICTS OF INTEREST}

The authors declare that there is no conflict of interest regarding the publication of this article.

\section{AUTHOR CONTRIBUTIONS}

DH Lee \& JH Lee designed the research study, analyzed the data, wrote the manuscript equally. All authors contributed to editorial changes in the manuscript. All authors read and approved the final manuscript.

\section{FUNDING INFORMATION}

This work was supported by the National Research Foundation of Korea (NRF) grant funded by the Korea government (MSIT) (No.2018R1C1B5046096), and a fund by Research of Korea Centers for Disease Control and Prevention (Emergency Department-Based Injury In-depth Surveillance). The funders had no role in study design, data collection and analysis, decision to publish, or preparation of the manuscript. Ethics approval and consent to participate. The KCDC is the authority for accessing the data. Informed consent was waived by the IRB because patient information was anonymized before the analysis.

\section{REFERENCES}

[1] Bertolote JM, De Leo D. Global suicide mortality rates-a light at the end of the tunnel? Hogrefe Publishing; 2012.

[2] Shah A. The relationship between suicide rates and age: an analysis of multinational data from the World Health Organization. International Psychogeriatrics. 2007;19:1141-1152.

[3] Shah A, Bhat R, Zarate-Escudero S, et al. Suicide rates in five-year age- 
bands after the age of 60 years: the international landscape. Aging Ment Health. 2016;20:131-138.

[4] Mejias-Martin Y, Luna Del Castillo JD, et al. Factors Associated with Suicide Attempts and Suicides in the General Population of Andalusia (Spain). Int J Environ Res Public Health. 2019;16:4496.

[5] Korean Statistical Information Service. South Korea Population by age and sex. 2018. accessable on: http://kosis.kr/statHtml/ statHtml.do?orgId=101\&tblId=DT_1IN1503\&vw_cd=MT ZTITLE\&list_id=A11_2015_1_10_10\&seqNo=\&lang_mode=ko\& language=kor\&obj_var_id=\&itm_id=\&conn_path=MT_ZTITLE.

[6] Service KSi. Elderly suicide in Korea: International Comparison Division: Trend of elderly suicide. Seoul; 2012.

[7] Organization for Economic Cooperation and Development. OECD Health at a Gglance 2019. 82p. https://www. oecd-ilibrary.org/docserver/d4e9f522-en.pdf? expires $=1600344221 \& i d=i d \& a c$ cname=guest\&checksum= B2C73BF80CA4B112840E79E30731BFB3.

[8] Korea Statistics. Annual Report on the Causes of Death Statistics, 2017. Daejeon, Republic of Korea: Statistics Korea.

[9] World Health Organization. World health statistics 2016: monitoring health for the SDGs sustainable development goals; World Health Organization; 2016.

[10] Lee H, Seol KH, Kim JW. Age and sex-related differences in risk factors for elderly suicide: Differentiating between suicide ideation and attempts. Int J Geriatr Psychiatry. 2018;33:e300-e306.

[11] Cheung G, Merry S, Sundram F. Do suicide characteristics differ by age in older people? Int Psychogeriatr. 2018;30:323-330.

[12] Kim M-H, Min S, Park K-C, et al. The Characteristics of Elderly Suicide Attempters in Korea: Comparison Study of Old-old vs. Young-old. Int J Neuropsychopharmacol. 2016;19:99.

[13] Shin KM, Cho SM, Hong $\mathrm{CH}$, et al. Suicide among the elderly and associated factors in South Korea. Aging Ment Health. 2013;17:109-114.

[14] Kim KH, Jeong KY, Lee JS, et al. The Characteristics of Elderly Patients With Suicide Attempts: A Comparative Study With Non-elderly Patients. Ann Geriatr Med Res. 2016;20:209-220.

[15] Kim EK. The risk factors of suicidal ideation by age groups among the elderly in Korea. Korean J Health Promot. 2015;15:54-62.

[16] Park JH, No YH, Wi DH. Clinical analysis of attempted suicide in the elderly. J Korean Soc Emerg Med. 2001;12:135-142.

[17] Vadysinghe AN, Senasinghe P, Sivasubramanium M, et al. Unnatural deaths of the elderly population of Sri Lanka: a descriptive analysis. Am J Foren Med Path. 2018;39:148-151.

[18] Cha ES, Chang S-S, Gunnell D, et al. Impact of paraquat regulation on suicide in South Korea. Int J Epidemiol. 2016;45:470-479.

[19] Stone DM, Holland KM, Bartholow BN, et al. Preventing suicide: A technical package of policies, programs, and practice. Atlanta, Georgia: National Center for Injury Prevention and Control, Centers for Disease Control and Prevention; 2017.

[20] National Emergency Medical Center. 2018 National Emergency Department Information System (NEDIS) statistics annual report. National Emergency Medical Center. accessable on: https://www.e-gen.or . $\mathrm{kr} / \mathrm{nemc} / \mathrm{statistics}$ annual_report.do?brdclscd $=02$.

[21] Korean Statistical Information Service. Population census. Statistics Korea. accessable on: http://kosis.kr/statHtml/statHtml.do? orgId=101\&tbIId=DT_1IN1503\&conn_path=I2.

[22] Cano-Montalbán I, Quevedo-Blasco R. Sociodemographic Variables Most Associated with Suicidal Behaviour and Suicide Methods in Europe and America. A Systematic Review. Eur J Psychol Appl to Leg Context. 2018;10:15-25.

[23] Teismann T, Forkmann T, Brailovskaia J, et al. Positive mental health moderates the association between depression and suicide ideation: A longitudinal study. Int J Clin Health Psychol. 2018;18:1-7.

[24] Balasubramaniam M. Rational Suicide in Elderly Adults: A Clinician's Perspective. J Am Geriatr Soc. 2018;66:998-1001.

[25] Battin MP. Choosing the time to die: The ethics and economics of suicide in old age. In: Ethical dimensions of geriatric care. Springer. 1987.p.161189.

[26] Kim S-H, Kim H-J, Lee J-S, et al. Pharmaceutical Drug Poisoning after Deregulation of Over the Counter Drug Sales: Emergency Department Based In-depth Injury Surveillance. J Korean Soc Clin Toxicol. 2018;16:141-148.

[27] Lim JY, Lee DH. Characteristics of drugs ingested for suicide attempts in the elderly. J Korean Med Sci. 2018;33:e86.

[28] Kim YR, Choi KH, Oh Y, et al. Elderly suicide attempters by selfpoisoning in Korea. Int Psychogeriatr. 2011;23:979-985.

[29] Jung S-Y, Eo E-K, Kim C-W, et al. Overview of poisoning admission in Korea-based on the hospital discharge injury surveillance data. J Korean Soc Clin Toxicol. 2008;6:16-24.

[30] Kim B-K, Jung S-Y, Jung K-Y. Characteristics of elderly patients with acute poisoning. J Korean Soc Clin Toxicol. 2010;8:61-68.

[31] Cha ES, Khang Y-H, Lee WJ. Mortality from and incidence of pesticide poisoning in South Korea: findings from National Death and Health Utilization Data between 2006 and 2010. PLoS One. 2014;9: e95299.

[32] Lee WJ, Choi SM, Kyong YY, et al. Clinical analysis of acute poisoning in elderly patients. J Korean Geriatr Soc. 2009;13:24-30.

[33] Kim JH, Cho JS, Kim JJ, et al. Comparison of Epidemiology and Outcomes of Patients with Intentional Poisoning by Age Groups: Single Center Observation Study. J Korean Soc Clin Toxicol. 2016;14:129-135.

[34] Lee WJ, Cha ES, Park ES, et al. Deaths from pesticide poisoning in South Korea: trends over 10 years. Int Arch Occup Environ Health. 2009;82:365-371.

[35] Moon JM, Chun BJ, Cho YS. The characteristics of emergency department presentations related to acute herbicide or insecticide poisoning in South Korea between 2011 and 2014. J Toxicol Environ Health A. 2016;79:466-476.

[36] Korea Statistics. Annual Report on the Causes of Death Statistics, 2018. Daejeon, Republic of Korea: Statistics Korea.

[37] Juurlink DN, Herrmann N, Szalai JP, et al. Medical illness and the risk of suicide in the elderly. Arch Intern Med. 2004;164:1179-1184.

[38] Özer E, Gümüş B, Balandiz H, et al. Evaluation of geriatric suicides in Turkey. J Forensic Leg Med. 2016;44:158-161.

[39] Park S, Ahn MH, Lee A, et al. Associations between changes in the pattern of suicide methods and rates in Korea, the US, and Finland. Int J Ment Health Syst. 2014;8:22

[40] Athey A, Overholser J, Bagge C, et al. Risk-taking behaviors and stressors differentially predict suicidal preparation, non-fatal suicide attempts, and suicide deaths. Psychiatry Res. 2018;270:160-167.

How to cite this article: Jae Hee Lee, Duk Hee Lee. Analysis of Characteristics, Methods of Suicide, and Clinical Outcomes in Elderly Suicide Attempters in South Korea by Age Subgroup. Signa Vitae. 2020;16(2):52-60. doi:10.22514/sv.2020.16.0065. 